\title{
Volunteers@your library: benefits and pitfalls of volunteers in hospital libraries
}

\author{
Mary McDiarmid and Ethel W. Auster
}

\begin{abstract}
The purpose of this survey was to explore the attitudes of hospital library managers toward the use of library volunteers. During April 2003 a questionnaire was mailed to 89 Ontario hospital library managers. One of the methods used to assess attitudes toward volunteers was to ask respondents to list two main benefits and pitfalls of using volunteers. Benefits of volunteer use identified by respondents included assisting with routine clerical tasks, saving staff time, providing an added value or service, assisting with a heavy workload, contributing to a positive public perception and promoting library service, keeping costs down, optimizing staff time, and doing special projects. Some of the pitfalls of volunteer use identified by respondents included unreliable volunteer attendance and commitment, and excessive training and retraining. The identification of volunteer benefits and pitfalls will help hospital library managers optimize the use of volunteers and implement changes in the way they manage volunteers.
\end{abstract}

\section{Introduction}

Hospital library managers, administrators, and library staff need to be aware of the influence and implications of the use of volunteers in their libraries. Being aware of both the benefits and pitfalls of using volunteers can enrich managers' knowledge of volunteers and assist hospital library managers in deciding whether to use volunteers. The Ontario Hospital Association conducted a survey of hospitals from 4 to 10 July 2003, and found that, without additional funding, $40 \%$ of hospitals would be unable to meet their payrolls, 2600 hospital beds would be eliminated, and 11500 staff positions would be cut [1]. Given this economic situation, a hospital librarian may willingly or unwillingly (because of administrative pressure), turn to volunteers in lieu of paid staff as a way to provide services.

The views of hospital librarians toward volunteers have mainly been promulgated in anecdotal accounts in the library literature [2-5]. These articles often debate whether volunteers are a benefit or a hindrance. Research articles addressing the benefits and pitfalls of volunteer use are scarce $[6,7]$. Benefits that have been reported in anecdotal accounts and research studies identify economic advantages such as cost savings gained from the ability to supplement staff when budgets are lean, expansion of library services, and staff time freed up so they may engage in more professional tasks. The value-added knowledge and enthusiasm that a volunteer brings to a position are also frequently cited as benefits. Difficulties with volunteers recounted in the anecdotal literature and research studies include problems maintaining library standards, frequent turnover of volunteers,

M. McDiarmid ${ }^{\mathbf{1}}$ and E.W. Auster. Faculty of Information Studies, University of Toronto, 140 St. George Street, Toronto, ON M5S 3G6, Canada.

${ }^{1}$ Corresponding author (e-mail: seajay@interlinks.net). recruitment problems, blurry boundaries between volunteer tasks and those of the paid positions, erosion of librarianship's professional identity, lack of volunteer accountability, threats to the job security of paid workers, and the morale of paid staff when volunteers are not wanted in the library.

\section{Methods}

A questionnaire design was chosen to collect data because it was the most effective and practical strategy given time and monetary constraints. The data collection instrument used in this research was an eight-page self-administered questionnaire consisting of six sections. The two questions relating to benefits and pitfalls were adapted from a previous questionnaire that examined the management and use of volunteers in 209 United Kingdom public library authorities [6]. The wording was altered to focus on hospital libraries instead of public libraries, and permission was obtained from the authors.

The target population of the research was managers of Ontario hospital libraries. A hospital library manager was defined as the person who is responsible for the operation of the library. This research was not restricted to librarians, that is, those holding a master's degree in library science, information science or information studies since it was expected that library managers in many of the smaller hospitals would not be librarians. Library managers were chosen as the target population since they are accountable for staffing decisions in their libraries. A hospital library volunteer was defined as a member of the hospital's youth or adult auxiliary program who is an unpaid worker and spends at least $1 \mathrm{~h}$ per week working in the hospital library. A total of 89 questionnaires were sent to the study population on 4 April 2003. Within 5 weeks, 80 questionnaires were returned. Seventy-nine useable questionnaires were analyzed from an adjusted sample 
Table 1. Benefits of volunteer use in descending order of frequency $(n=158)$.

\begin{tabular}{lllr}
\hline Benefit & $\begin{array}{l}\text { Managers currently } \\
\text { using volunteers }\end{array}$ & $\begin{array}{l}\text { Managers not currently } \\
\text { using volunteers }\end{array}$ & Total \\
\hline Assistance with routine clerical tasks & $25(24.7)$ & $8(14.2)$ & $33(21.0)$ \\
Save staff time & $14(13.8)$ & $8(14.2)$ & $22(14.0)$ \\
Provide an added value or service & $13(12.8)$ & $5(8.9)$ & $18(11.4)$ \\
Benefits for volunteers & $5(4.9)$ & $6(10.7)$ & $11(7.0)$ \\
Lessen the workload & $6(5.9)$ & $3(5.3)$ & $9(5.7)$ \\
Positive public perception of service & $8(7.9)$ & $1(1.7)$ & $9(5.7)$ \\
Contribute to cost savings & $4(3.9)$ & $3(5.3)$ & $7(4.4)$ \\
Dependability and reliability & $5(4.9)$ & $1(1.7)$ & $6(3.8)$ \\
Enhancement of staffing levels & $6(5.9)$ & $0(0)$ & $6(3.8)$ \\
Assistance with special projects & $4(3.9)$ & $2(3.5)$ & $6(3.8)$ \\
No response provided & $11(10.8)$ & $20(35.0)$ & $31(19.6)$ \\
\hline
\end{tabular}

Note: Values in parentheses indicate percentage of responses within each group.

of 86 eligible respondents, resulting in a response rate of $92 \%$ for useable questionnaires.

\section{Findings}

Provided below are some of the findings of the statistical analysis for all respondents. Of the Ontario hospital libraries surveyed, $65 \%$ used volunteers in their libraries. Of the 28 libraries that were not currently using volunteers, only 8 had never used them. There were 119 library volunteers who worked a total of $728 \mathrm{~h}$ per week, an average of $14.6 \mathrm{~h}$ per library per week. The number of volunteers used per library ranged from 1 to 45. The 300-399 hospital bed group had the largest percentage of volunteer use at $26 \%$. Of managers using volunteers, $67 \%$ believed they were not adequately staffed, while $37 \%$ of those not using volunteers shared this belief.

\section{Benefits of volunteer use}

Questionnaire respondents were asked to identify what they believed to be the two main benefits of using volunteers. The number of comments was expected to be 158 since there were 79 respondents; however, many respondents (20\%) did not list any benefits of volunteers, and others specified only one benefit. When managers indicating "no response" were examined according to volunteer use, 35\% of managers from libraries not using volunteers failed to identify any benefit while only $11 \%$ of managers from libraries using volunteers did not specify any benefits. If respondents did not list any benefits, these nonresponses were included in calculating the categories of total responses because the failure of a respondent to cite any benefit provided feedback about the managers' beliefs about the value of volunteers.

In descending order of selection, the benefits of volunteer use cited by respondents included assistance with routine clerical tasks $(21 \%)$, saving staff time (14\%), providing an added value or service (11\%), assistance with a heavy workload (6\%), contributing to a positive public perception and promotion of library service (6\%), keeping costs down (4\%), dependability and reliability (4\%), enhancement of staffing (4\%), and special projects (4\%). Table 1 summarizes the main benefits identified in order of most frequently cited benefit, as well as the percentage of responses within each volunteer use group.

\section{Assistance with routine clerical tasks}

The most frequently cited benefit of volunteer use, reported by $33(21 \%)$ respondents, was having volunteers assist with routine clerical tasks. Almost $25 \%$ of managers from libraries using volunteers (users) and $14 \%$ of managers from libraries not currently using volunteers (nonusers) identified this as a benefit. Many managers indicated that having volunteers perform mundane and menial tasks enabled paid library staff to find time to concentrate on more professional endeavours. One respondent currently using volunteers commented, "Provides some clerical support and support for routine tasks". Nonusers expressed similar views as shown in the following comments: "Do day-to-day things that get shoved aside", and "Relieves paid staff of clerical tasks".

\section{Saving staff time}

The second most frequently cited benefit of volunteer use specified by $14 \%$ of users and nonusers was saving library staff time. This benefit is related to providing assistance with routine clerical tasks. Library managers explained that volunteers performing routine tasks freed up staff time for more technical and professional tasks. Respondents expressed this through the following comments: "Frees up my time for more professional tasks", "Allows regular library staff time for important tasks", and "More time can be freed for other more complex tasks".

\section{Providing an added value or service}

Eleven percent of all managers believed that volunteers provided added value to existing library services. Specifically, the presence of volunteers enabled the library to remain open in the absence of paid staff. Thirteen percent of users and $9 \%$ of nonusers cited this as a benefit. Examples of comments from users of volunteers included "Allows library to remain open and provides skeleton service when staff absent", "Can provide back up to keep library open when a small library is short-staffed", "Provides a presence when staff unavailable". A manager from a library not using volunteers made a similar comment: "A well-trained volun- 
teer with the proper skills can be helpful in keeping the library open (if at a meeting)."

Managers indicated that, in some cases, volunteers bring special skills and experience to the library. This allowed libraries to extend an existing service or provide a new service that would not otherwise be offered without additional paid staffing. One respondent from a library using volunteers commented, "It helps the library to do more as a service than they could without a volunteer unless they had more staff." "Volunteers may have other skills that can be used, e.g., desktop publishing for marketing", commented one respondent. Managers from libraries not using volunteers expressed similar sentiments regarding this benefit of volunteer use.

\section{Remaining benefits}

The remaining benefits of volunteer use were identified by less than $10 \%$ of all respondents. Almost $6 \%$ of all respondents indicated that assistance with a heavy workload was a benefit of using volunteers. A manager from a library using volunteers described how "volunteers help cope with tremendous workload for an understaffed one-person library". Respondents also believed that having volunteers in the library helped to promote the library's service by demonstrating to hospital administrators and others that the library is a caring place. Almost $6 \%$ of respondents indicated that volunteers were beneficial because they helped to promote the library's service. A manager from a library using volunteers wrote, "As the role, responsibility, and scope of libraries continue to evolve, volunteers help a community to understand the value of the library to the hospital." Another commented, "Using volunteers shows the hospital that you care."

Only $4 \%$ of all respondents identified four further benefits of using volunteers. These least-cited benefits included special projects, keeping costs down, dependability and reliability, and enhancement of staffing levels in the library. Managers reported that volunteers could undertake special projects that either required too much staff time or were not critical enough to warrant the staff's time but were nice to have done. Volunteers were also perceived as beneficial because some managers believed they helped to keep costs down. One manager not currently using volunteers caught the general mood well by describing volunteers as "a costsaving gesture on the part of management". Five respondents (5\%) from libraries using volunteers identified dependability and reliability of volunteers as a benefit, while only one manager from a library not using volunteers $(2 \%)$ believed this was a benefit of using volunteers.

A typical comment that reflected belief in the reliability and dependability of volunteers was "my volunteer is reliable and consistent - he contributes greatly to the operation." "My volunteer has been here approximately 15 years and knows what she is doing", expressed the confidence shown by one respondent. Six managers (4\%) currently using volunteers commented that the presence of volunteers enhanced their staffing levels. Managers from libraries not using volunteers did not mention this item as a benefit. A respondent suggested that the presence of volunteers doing work in the library sends a message to administration and "proves I need the help". Another respondent suggested that "small libraries with one staff need help" and volunteers provide this needed boost to staffing.

Instead of listing benefits that volunteers bring to the library, several respondents $(11 \%)$ listed benefits that volunteers received from being able to work in the hospital library. The benefits for volunteers included work experience and training for future library students. Examples of comments from users included "Most volunteers we've had are seeking job experience and volunteering helps them" and volunteering "enables the public and volunteers to understand the work of a hospital library". Comments from nonusers were similar. Volunteering was believed to "provide working experience for résumés" and "exposure to the profession for potential students of library studies".

\section{Pitfalls of volunteer use}

Questionnaire respondents were asked to cite what they believed to be the two main pitfalls of using volunteers. The number of comments describing the pitfalls of volunteer use was expected to be 158 since there were 79 respondents. However, $20 \%$ of all respondents failed to specify any pitfalls of volunteer use. When the "no response" respondents are broken down according to volunteer use, approximately $20 \%$ of managers from libraries using volunteers and $21 \%$ of managers from libraries not using volunteers did not specify any pitfalls of volunteer use. These nonresponses were included in calculating the categories of total responses because the failure of a respondent to cite any pitfalls of volunteer use also provided feedback about managers' beliefs about the value of volunteers.

In descending order of selection, pitfalls of volunteer use cited by respondents included unreliable volunteer attendance and commitment (19\%), excessive training and retraining $(18 \%)$, more supervision needed (13\%), negative public perception of library service $(8 \%)$, negative impact on staffing levels $(7 \%)$, reduction in standards and quality of work (7\%), negative impact on staff time (4\%), finding appropriate tasks for volunteers to perform (3\%), difficulties in recruitment of appropriate volunteers (1\%), negative impact on library budget $(1 \%)$, and other pitfalls (1\%). Table 2 summarizes the main pitfalls identified in order of most frequently cited, as well as the percentage of responses within each volunteer use group.

\section{Unreliable volunteer attendance and commitment}

The most frequently cited pitfall of using volunteers specified by all respondents was related to managers' perception that volunteer attendance and commitment to the library is undependable and unreliable. Thirty managers (19\%) viewed the unreliability and lack of commitment of volunteers to be a pitfall. This was also the most cited pitfall by the subgroup of managers who are currently using volunteers, with slightly more than $20 \%$ of managers specifying it as a drawback. For managers not currently using volunteers, this was the second most frequently cited pitfall, identified by $16 \%$ of these respondents. Some managers were brief and commented merely that volunteers were unreliable, while others were more descriptive and offered an explanation that included factors such as a volunteer's attendance, commitment, and availability. Poor attendance and a lack of commitment of volunteers were noted as issues in the fol- 
Table 2. Pitfalls of volunteer use in descending order of frequency $(n=158)$.

\begin{tabular}{|c|c|c|c|}
\hline Pitfall & $\begin{array}{l}\text { Managers currently } \\
\text { using volunteers }\end{array}$ & $\begin{array}{l}\text { Managers not currently } \\
\text { using volunteers }\end{array}$ & Total \\
\hline Unreliable attendance and commitment & $21(20.3)$ & $9(16.3)$ & $30(18.9)$ \\
\hline Excessive training and retraining & $17(16.5)$ & $11(20.0)$ & $28(17.7)$ \\
\hline More supervision needed & $14(13.5)$ & $7(12.7)$ & $21(13.2)$ \\
\hline Negative public perception of service & $9(8.7)$ & $3(5.4)$ & $12(7.5)$ \\
\hline Negative impact on staffing levels & $6(5.8)$ & $5(9.0)$ & $11(6.9)$ \\
\hline Reduction in standard and quality of work & $7(6.7)$ & $4(7.2)$ & $11(6.9)$ \\
\hline Negative impact on staff time & $3(2.9)$ & $3(5.4)$ & $6(3.7)$ \\
\hline Finding appropriate volunteer tasks & $4(3.8)$ & $0(0)$ & $4(2.5)$ \\
\hline Finding suitable volunteers & $2(1.9)$ & $0(0)$ & $2(1.2)$ \\
\hline Negative impact on library's budget & $0(0)$ & $1(1.8)$ & $1(0.6)$ \\
\hline No response provided & $20(19.4)$ & $12(21.8)$ & $32(20.2)$ \\
\hline
\end{tabular}

Note: Values in parentheses indicate percentage of responses within each group.

lowing comments: "Volunteers can come and go as they please", and "may not come on a regular basis" and volunteers often "take days off when family illness, etc., happens". One respondent expressed concern that "projects that require daily attention cannot be given to them due to the continuity of attending to these on a regular basis". Managers from libraries not using volunteers expressed similar beliefs: "Because they are volunteering and are unpaid, all other activities take precedence and they may not keep their commitments within the library."

\section{Excessive training and retraining}

The excessive training requirements of volunteers were the second most frequently cited pitfall specified by $18 \%$ of all respondents. Twenty percent of managers from libraries not using volunteers specified training as a pitfall. It was the most frequently cited pitfall identified by this group of managers. Almost $17 \%$ of managers from libraries currently using volunteers specified training as a pitfall. For these managers it was the second most frequently cited. Both groups of managers had similar comments about the problems of training volunteers. Specifically, the time spent training volunteers and the need for constant retraining were perceived as drawbacks. Several individuals were critical about spending time training and retraining. "You do not want to spend too much time training since they might leave", commented one respondent. "Not enough time is spent each week doing tasks and retraining is a problem", commented another. "Constant retraining is needed for some volunteers", commented a third. Managers not using volunteers also believed that training and retraining were problematic. One respondent stated that it was a "waste of time teaching volunteers who move on quickly. Then you have to start over again."

\section{More supervision needed}

The third most frequently cited pitfall of volunteer use was the supervision of volunteers. This pitfall was cited by a similar percentage of managers using volunteers and managers not using volunteers, $14 \%$ and $13 \%$, respectively. Supervisory issues mentioned by managers included the need to control inappropriate social behaviour of volunteers and the need to control volunteer activities that overstep the boundaries set by library staff. A respondent from a library using volunteers commented, "Sometimes those who started working in the library long before the librarian find it difficult to follow instructions." Another user commented, "Volunteers will do work meant for professionals and provide patrons with inaccurate or insufficient information." One respondent noted unrealistic expectations held by some volunteers: "We have a very clear job description and an interview yet some want only to do the 'fun stuff', talk to patrons and search the Internet." One user cautioned that "many are unwilling/ unable to do heavy lifting, copying that constitutes much of our daily activity." A manager from a library not using volunteers noted that "Unsupervised at times, we have had complaints about behaviour of volunteers in our absence."

\section{Remaining pitfalls}

The remaining pitfalls of volunteer use were identified by less than $10 \%$ of all respondents. Almost $8 \%$ of all respondents were concerned that the public perception of library service and professionals is diminished by the use of volunteers in a hospital library. In particular, they felt that the public might view library work as unskilled and not requiring the services of specially trained staff. One respondent expressed concern that the "administration will view volunteers as being able to do professional work and, therefore, not hire professional staff with training." Another commented that administrators might develop the view "that the library can be run by volunteers". The use of volunteers "makes the library profession look cheap and like a woman's job, i.e., as nothing better to do for a lonely homemaker", expressed yet another respondent.

Volunteers were also perceived to be a disadvantage to maintaining staffing levels in hospital libraries. Managers pointed out that using volunteers may lessen the workload, but this in turn makes it difficult to justify that additional paid staff are necessary to accomplish these tasks. Another aspect of staffing concerns was the issue of substitution. Managers expressed concern that volunteers were taking the place of paid staff. Six percent of managers using volunteers and $9 \%$ of managers not using volunteers viewed this as a pitfall. A manager from a library using volunteers advised managers "to be careful that management doesn't see volunteers as able to replace library staff." One manager from a library not using volunteers noted that "if the librarian is 
part-time, volunteer use does not help her acquire full-time status."

Seven percent of all respondents identified the poor quality of work performed by volunteers as a pitfall of their use. Managers commented that the work of volunteers could be inconsistent, especially if two are doing the same task. Some managers believed volunteers were not suitable for the attention to detail that is needed. Advanced age and a lack of technical expertise were also mentioned as contributing factors to the poor quality of work performed by volunteers. One manager raised the issue of patient confidentiality and others had concerns about the lack of accountability if volunteers did something harmful or wrong.

The remaining pitfalls of volunteer use were cited by less than $4 \%$ of all respondents. These less frequently mentioned pitfalls included negative impact on staff time, finding suitable volunteers to work in the library, and the negative impact on the library's budget. Some respondents believed volunteers were time consumers rather than time savers. One user's comment summarized the concerns surrounding time management:

More time tends to get spent on less professional tasks before and during the time volunteers work (preparation, instruction, working in tandem or keeping one step ahead of volunteers). Being very part-time myself, sometimes I wonder if it's worth it to have a volunteer (ambivalent).

A related difficulty expressed by some managers was that they found themselves scrambling at times to ensure that volunteers had an appropriate and sufficient number of tasks to perform during their hours of service. Recruitment of volunteers for hospital libraries was not perceived as a problem. Only two managers from libraries using volunteers wrote of the difficulty of finding an appropriate volunteer: "One has to search diligently for dedicated, reliable, educated new volunteers to replace a good volunteer who can carry out any duty assigned." Only one respondent identified the negative impact the volunteers could have on a library's budget as a pitfall. This manager commented, "Volunteers allow management to justify limiting a library's budget."

\section{Discussion}

This research identified the benefits that some hospital library managers have realized from using volunteers in their libraries. It has also identified potential pitfalls that could be encountered through volunteer use. Ensuring that library managers address any potential pitfalls in a proactive, not reactive, manner could alleviate many of the drawbacks associated with volunteer use. By clearly defining roles, setting limits and standards for performance, providing appropriate training, and documenting these requirements in writing, libraries already using volunteers and those who are considering using volunteers in their libraries may optimize their use of volunteers in the hospital library.

The roles of volunteers and staff, and the expectations of both groups, need to be clearly defined. Library staff and volunteers need to understand the scope of duties that a volunteer would be expected to perform. Staff may become resentful if volunteers are only given the "fun" things to do. The most successful volunteer relationships described by managers in our research were ones in which the library staff went out of their way to ensure they matched the volunteer to the task and took extra time and attention to ensure the volunteers were comfortable and happy with their assigned duties. It is also important for library managers to regularly evaluate whether the hospital library volunteers are helping or hindering the library's mission. Libraries with many volunteers, as well as those with long-term volunteers, need to seriously consider whether the presence of volunteers delays the creation of new library staff positions or whether the library is overly dependent on volunteers to perform daily activities. Some Ontario hospital library managers felt the impact of their dependence on volunteers to accomplish the daily, routine tasks. During the severe acute respiratory syndrome (SARS) crisis in Ontario, volunteers were banned from hospitals, and some library managers were subsequently overburdened with a backlog of tasks that were usually performed by volunteers.

Managers believed the unreliability and undependability of volunteers was a key pitfall of volunteer use. It is impractical to hold volunteers to the same standards of attendance that would be expected of paid employees. However, volunteers should be expected to adhere to the same attendance reporting procedures as paid staff, e.g., calling in to report absence. Managers must be understanding and tolerant of library volunteers who require extensive time off during summer and winter months for vacation. Managers must also be prepared for the retraining that will be needed when volunteers resume their duties after a period of absence.

Training and retraining was another key pitfall that can be addressed in a proactive manner. One way to lessen the impact of the training requirements for library volunteers is to create a written procedure manual outlining the duties volunteers may be asked to perform. This manual could then be consulted before asking library staff for help. Without an appropriate volunteer training plan, libraries will not realize the benefit of saving staff time. Instead, they will find that a great deal of time is spent training or retraining volunteers.

By clearly defining roles, setting limits and standards for performance, providing appropriate training, and documenting these requirements in writing, the library manager will maintain control and keep service levels in check. An example of the importance of supervision and control of volunteers is seen in the following description written by a manager who was unwillingly using volunteers.

It has been a nightmare using volunteers in our library. I seriously question the ethics of this situation. Volunteers are permitted to do literature searches for patrons without referring to staff. I have seen patrons leave the library with inaccurate or insufficient information and have not been allowed by administration to correct the situation. Administration sees the bottom line of money and uses volunteers in place of hiring enough professional staff. Volunteers here more or less run the show and we can say very little.

In conclusion, to be successful, a library volunteer program needs the cooperation and support of all library staff. One of the questions posed in our questionnaire asked managers whether their library staff resented volunteers working in their libraries. From the responses, it was apparent that managers did not know whether their staff resented volunteers. The use of volunteers will not be successful if paid library staff members do not want to work with them. 
Managers also need to be aware of changes in the outlook of paid staff toward volunteers over time. For example, in times of budget cutbacks, paid staff might begin to resent the presence of volunteers and perceive them as a replacement for paid staff. Library volunteers should be neither a quick fix nor a permanent solution for a library's understaffing problem.

\section{Acknowledgements}

Funding for this research was provided through a Chapter Initiative Grant from the Canadian Health Libraries Association / Association des bibliothèques de la santé du Canada.

\section{References}

1. Ontario Hospital Association. Stalled provincial funding jeopardizes patient care in Ontario [monograph on the Internet]. Toronto: The Association; 2003 [cited 2003 Sep 3]. Available from:
http://www.oha.com/oha/MEDIA.NSF/ 2a0bbdbfbc9c4018052563bd00574458/ c1c629df124e1800052563ca00307a1b?OpenDocument.

2. Angle JG. Volunteers in a hospital library. Hosp Libr. 1977;2(10):2-3.

3. Hall A, Love B. Library volunteers in a unionized environment. Access: The Official Publication of the Ontario Library Association. 2003;9(2):24-7.

4. Lingle VA. Volunteers in the medical library: issues and suggestions for their use. Med Ref Serv Q. 1984;3(4):45-56.

5. Treaster B. Volunteers: even more valuable now. Nat Netw. 2002;27(1):19.

6. Cookman N, Haynes D, Streatfield D. The use of volunteers in public libraries: a report to the Library Association [monograph on the Internet]. London: The Library Association; 2000 [cited 2003 Nov 28]. Available from: http://www.la-hq.org.uk/ directory/prof_issues/vols.pdf.

7. Jervis B. Unpaid volunteers: burden or bonus? Public Library Journal. 2000;15(1):15-6. 